\title{
Fuzzy hierarchical evaluations of business website performance with application to luxury hotels
}

\author{
Shanshan $Q i^{1}$
}

Received: 07/04/2011

\begin{abstract}
${ }^{1}$ School of Hotel \& Tourism Management, The Hong Kong Polytechnic University, Hung Hom, Kowloon, Hong Kong, Phone: (852)3400-2332, fax: (852) 2362-9362, e-mail: ss79802008@yahoo.com.cn
\end{abstract}

Supervisor: Professor Rob Law, PhD and Professor Dimitrios Buhalis, PhD

Institution awarding the Ph. D. Degree: School of Hotel and Tourism Management, Hong Kong Polytechnic University

Date of defence: $17^{\text {th }}$ March 2011

(c) 2011 International University College. All rights reserved

Citation: Shanshan, Q. (2011), Fuzzy hierarchical evaluations of business website performance with application to luxury hotels. Doctoral dissertation summary. European Journal of Tourism Research 4(2), pp. 217-220

\section{Goal and objectives of the dissertation Goal}

This study evaluates usefulness performance of hotel websites by integrating website functionality and usability, a fuzzy hierarchical TOPSIS model was designed for calculation process.

\section{Objectives}

- to develop a comprehensive list of attributes for website functionality based on literature; - to establish a comprehensive list of attributes for website usability based on literature;

- to integrate the applicability of these two lists in the Chinese and international context; and

- to assess the usefulness (functionality and usability) performance of different groups of hotel websites (China-based and international luxury hotels) using a fuzzy TOPSIS hierarchical model from users' perception.

\section{Methodology}

The research combines both qualitative and quantitative methodologies to achieve the objectives of developing a website usefulness evaluation framework and evaluating usefulness performance of websites. The methodology section includes three stages. At stage one, a qualitative approach that involved Chinese and international focus groups formed by population of tourists who have purchased or searched travel products in the past 12 months. New usefulness attributes for websites were discovered from Chinese online travelers, and then the applicability of these attributes in an international context was tested. The result of group discussions was employed to establish a new set of website usefulness evaluation measurement.

Stage two aimed to collect the perceived importance of website usefulness attributes 
from Chinese and international respondents who have visited or searched luxury hotel websites. The performance scores of selected hotel websites were generated from Chinese and international evaluators. For a normal sampling distribution the minimum sample size should be 30 (Mendenhall \& Beaver, 1995). Thus, the researcher randomly selected 30 international luxury hotels from the publication "The Leading Hotels of the World" (Romanella \& Chung, 2007). China-based luxury hotels were selected from the top 30 Chinese cities that received more than 200,000 inbound tourists. Using Ctrip.com, the top online travel operator website in China that provides a starrelated hotel list, hotels were randomly selected.

The third stage used a modified fuzzy hierarchical TOPSIS model that integrates the perceived importance of website usefulness into hotel website evaluation results, which represent the overall performance of selected luxury hotel websites. The research data were mainly calculated by newly developed fuzzy model.

\section{Results}

A new website usefulness evaluation list was produced and the applicability of the new list was tested by both international and Chinese consumers. The importance of each usefulness attribute was indicated by Chinese and international consumers, respectively. Results revealed that Chinese and international users had similar perceptions of website functionality. The most important attribute is "reservation information". In particular, "hotel location", "room rate", "secured payment system", "hotel descriptions", and "hotel facilities" were evaluated as high importance by both international and Chinese luxury hotel consumers. On the usability aspect, both international and Chinese consumers indicated that "Access speed of website", "information credibility", and "website learnability" was the most important among all usability attributes. Different perspectives were observed between these two groups of consumers. International consumers care more about how to explore a website while Chinese consumers considered website accessibility and ease of use as more important attributes. Therefore, hoteliers should treat these two groups of consumers separately during their website development.

The usefulness performance of 30 Chinabased and 30 international luxury hotel websites was evaluated by both Chinese and international evaluators, respectively. A modified fuzzy TOPSIS method was employed to combine the findings of consumers perceptions and website evaluation results. Empirical findings demonstrated that international luxury hotel websites yield better performance in both functionality and usability aspects. Chinese luxury hotel websites merely provided basic functions and, had relatively weak usability performance. The best and worst performing hotel websites were employed as examples to help hoteliers improve and evaluate their websites.

This research sheds light on using a new website evaluation approach which employed scientific algorithms combine with website evaluation measurements. It also gives insights into differences between Chinese and internationals online travelers and a comparison between China-based and international luxury hotel websites' usefulness performance.

\section{Theoretical conclusions}

Due to the importance of the Internet many research studies on website evaluation have presented various approaches to improve the quality of commercial websites. These approaches may not be adequate to measure factors that motivate users to browse and make purchases on travel websites. The existing tourism literature simply does not feature any commonly agreed-upon standards or techniques for website evaluation. Thus, an efficient evaluation approach which combines standard website usefulness evaluation measurement with scientific computation methods is appreciated.

Since China has a large population and a huge market of potential customers on travel service, it is of paramount importance to investigate Chinese consumers' perceptions on travel websites. However, China' online tourism and 
hospitality market remains uncertainties on Chinese consumers' needs on hotel websites and a comparison between Chinese and international consumers' perceptions on hotel website performance is needed.

This research adds to existing literature with a novel website evaluation approach and produced a new website usefulness evaluation framework that can be applied in both Chinese and international contexts. A fuzzy TOPSIS model is designed for result computation process to produce scientific evaluation results.

\section{Practical applications of the dissertation}

Hotel website owners should endeavor to achieve better website usefulness performance to remain competitive and attract more customers. This research has investigated the difference in perceptions between Chinese and international users of hotel websites in terms of usefulness, which comprises usability and functionality. Hoteliers should treat these two groups of consumers separately to fulfil their varying requirements. The research findings also indicated the usefulness performance of China-based and international hotel websites. The best and worst performing Chinese and international luxury hotel websites were presented with examples that can assist hoteliers during their website design and improvement process.

\section{Content of the dissertation}

\section{Abstract of chapter one}

This chapter introduces the study. Firstly, it introduces the research background of the importance of Internet and online travel market, followed by a general description of China online tourism market and why testing website performance is important. Afterwards, the scope of this research was introduced. Research significance objectives, contributions and thesis structure are presented at the end of the chapter.

\section{Abstract of chapter two}

This chapter reviews published articles on Internet technologies and applications to tourism industry. It introduces China's etourism market and the uniqueness of Chinese online users. This chapter primarily aims to identify research gaps in the existing literature and review the use of website evaluation models in tourism. These evaluation methods are generally classified into different categories, and each category is explained. Content of website performance (Website usefulness) was extended to evaluate hotel website performance.

\section{Abstract of chapter three}

This chapter proposes a sketch of the research methodology. It outlines the research methodology into four major steps with the goal of addressing the research problems. This research adopted an integrated approach and used a qualitative method to discover new findings from Chinese online travelers. A quantitative method was used to collect views on the importance of website usefulness from both Chinese and international luxury hotel consumers. Finally, a qualitative method was adopted to obtain the websites' actual performance.

\section{Abstract of chapter four}

This chapter introduces the basic concept of fuzzy theory and why choose fuzzy TOPSIS model. It illustrates in detail the modified fuzzy model and the purpose of using the formula. Evidently, the modified fuzzy TOPSIS model successfully weights the evaluation criteria by a hieratical structure. The defuzzified final result reflects the hotel website performance in crisp value, which provides a readable result for both hoteliers and researchers.

\section{Abstract of chapter five}

This chapter presents research findings and starts with a detailed analysis of group discussion including newly discovered attributes for hotel websites. The importance of website usability and functionality is then discussed. This section is followed by a discussion of the overall performance of Chinese and international luxury hotel websites, respectively. Subsequently, the usability and functionality performance of Chinese and international luxury hotels is described. The last section compares the differences between Chinese and international luxury hotel website performance. Differences between Chinese and international consumers' 
perceptions are also provided. Additionally, this chapter presents the profiles of group discussion members, the respondents of surveys and the website evaluators.

\section{Abstract of chapter six}

This chapter presents the conclusion of the study. A general overview of the study is presented, followed by the achievement of research objectives. Subsequently, research limitations with recommendations for future research suggestions are provided.

\section{References}

Mendenhall, W., \& Beaver, R. (1995). Sampling distributions. In Hinrichs, C. (Eds.), A brief course in business statistics (pp. 176-211). Belmont, CA: Duxbury Press.

Romanella, J. J., \& Chung, D. (2007). The leading hotels of the World.

Complimentary Copy printed in Singapore. Available online at: www.Ihw.com [accessed 22 September 2008]. 